\title{
On the Study of Risk Factors of Ca. Cervix and Ca. Breast: a Case Study in Assam
}

\author{
Lipi B. Mahanta, Dilip C. Nath and Nijara Rajbongshi
}

\begin{abstract}
Ca.cervix and ca.breast are the most common life threatening cancers among women worldwide and the same is true for north east region of India also. So these two cancers remain a serious public health problem worldwide. Therefore more research work on the risk factors for ca.cervix and ca.breast is needed to better understand its etiology and pathogenesis. With this background this study is conducted to observe the possible factors such as socio-economic, marital etc., which may lead to the occurrence of these cancers in our region.
\end{abstract}

For conducting this study we collect data by interviewing the patient registered in the B. Barooah cancer research institute which is the main sources of cancer data in Assam. Here we take 30 diagnosed cases each for ca.cervix and ca.breast and plot the data in a cross tabular form and analyze different factors and finally we try to abstract the conclusion from these tables.

From the study it is revealed that there is strong evidence between the cancer type (ca.breast and ca.cervix) and the following risk factors: family income ( $p=.017)$, age at marriage $(p=.031)$, age of the patients $(p=.017)$, number of children $(p=.001)$, age at first child birth ( $p=.003)$, oral contraceptive used $(p=.028)$. It has been further observed that most of the patients are house wives and non vegetarian. Moreover it is seen that of the two types of cancer the Bengali population of the state are more afflicted by ca.breast whereas the Assamese population are more afflicted by ca.cervix.

Keywords--- Epidemiology, Risk Factors, Ca.Cervix, Ca.Breast

\section{INTRODUCTION}

$\mathrm{R}$ ecent times have seen an increase in the incidence of cancer. This is mainly attributed to urbanization, industrialization, lifestyle changes, population growth and increased life span (in turn leading to an increase in the elderly population). In India, the life expectancy at birth has steadily risen from 45 years in 1971 to 62 years in 1991, indicating a shift in the demographic profile [27]. It is estimated that life expectancy of the Indian population will increase to 70 years by 2021-25.2 This has caused a paradigm shift in the disease pattern from communicable diseases to non-communicable diseases like cancer, diabetes and hypertension.

Cancer prevalence in India is estimated to be around 2.5 million with over 800000 new cases and 550000 deaths occurring each year due to this disease [22]. And among the

Lipi B. Mahanta, Assistant Professor (II), Central Computational and Numerical Studies, Institute of Advanced Study in Science and Technology, Guwahati-35, Assam, India. E-mail: lipimahanta@yahoo.co.in

Dilip C. Nath, Professor, Department of Statistics, Gauhati University, Guwahati-14, Assam, India.E-mail: dilipc.nath@gmail.com

Nijara Rajbongshi, JRF, Central Computational and Numerical Studies, Institute of Advanced Study in Science and Technology, Guwahati-55, Assam, India.E-mail: nizara12341@gmail.com most common cancers that occur, cervix and breast is the leading site of the cancer among the female population of India. The impact of cancer is far greater than mere numbers. Its diagnosis causes immense emotional trauma and its treatment, a major economical burden, especially in a developing country like India. Assam is one of the states of India which faces the same problem. The incidence rate of these two types of cancer occupies the highest place in Assam also [23].

Cervical Cancer is a disease which women suffer from and it is one of the few cancers with a readily detectable and treatable precursor stage. There are two distinct conditions, 'carcinoma in situ' and 'invasive cervical cancer'. The former refers to the development of pre-malignant lesions whilst the latter is a more advanced stage in which a tumour is present [1].

Breast cancer is one of our times' biggest health threats. The world over, millions of women suffer from this form of cancer, and medical science has now moved in long and positive forward strides in the detection and cure of this disease. Breast cancer is a type of cancer that starts in the cells of the breast. The disease occurs most often in women, but it can affect male breast as well. Three main kinds of tissues present in the female breast are:

- Lobules: the milk-producing glands,

- Ducts: these are tiny tubes that carry the milk produced in lobules to the nipple and

- Stroma: fatty tissue and connective tissue surrounding the ducts, lobules, blood vessels and lymphatic vessels make the stroma (or the supporting tissue of the breast).

Breast cancer can develop in any of these tissues. Several types of cancer can occur in the breast. Most breast cancers, however, are either ductal carcinomas or lobular carcinomas. Other types of breast cancer occur less commonly [17].

Ca.Breast and Ca.Cervix are curable if it is detected in the early stages, but more than $70 \%$ of the cases report for diagnostic and treatment services in the advanced stages of the diseases, which has lead to poor survival and high mortality rate [11]. So these two cancers remain a serious public health problem worldwide. Therefore more research work on the risk factors for Ca.Cervix and Ca.Breast is needed to better understand its aetiology and pathogenesis so that we can take different programmes to control the highest incidence of these two types of cancer. With this background we started this study in our region including these two cancers and tried to observe different factors associated with Ca.Breast and Ca.Cervix. 


\section{MATERIALS AND METHODS}

\section{A. Selection of Location and Subjects}

This study was conducted in the B. Barooah Cancer Research Institute, Guwahati, Assam which is the main sources of cancer related data in Assam and most of the patient whose economic condition is very poor usually comes to this institute for cancer treatment because there are various facilities for economically poor patient. Earlier study revealed that carcinoma of the uterine cervix primarily affects women from the lower socioeconomic class and those with poor access to routine medical care. We collected the information required for our study by interviewing the patients who were clinically diagnosed as cancer patient and also collected information from the case files recorded in the hospital record. For incomplete data we tried to contact them over phone and get the information.

\section{B. Collection of Data}

\section{i. Background Information}

To obtain all relevant information from the patients a structured questionnaire was designed containing questions related to the basic background of the patient such as place of origin, age, religion, mother tongue, education, family income etc. Also the other factors- age at marriage, no. of children, age at first child birth, menopause, menarche, oral contraceptive used, chewing habits, dietary habit etc. related with the occurrence of the both types of cancers were included. This Interview Schedule was pre tested for reliability and validity using appropriate methods [26]. After appropriate testing the schedule was finalized and used it to collect the information.

\section{ii. Study Design}

This was a cross sectional study design consisting of women of any age having diagnosed with breast or cervix cancer.

\section{iii. Risk Factors associated with Ca.Cervix and Ca.Breast}

According to epidemiological studies, $80-90 \%$ of all cancers are due to environmental factors of which, lifestyle related factors are the most important and preventable [31].

Risk factors associated with cervical cancer:

Age: Most cases are found in women younger than 50 . However, the risk of cervical cancer does not disappear all together with age. Almost $20 \%$ of women with cervical cancer are diagnosed when they are over 65 .

Race: Researchers believe that population groups with low economic statuses, are less likely to receive Pap smears. Pap smears increase the likelihood that cervical cancer will be detected at pre-cancerous or very early cancerous stages when treatment is most successful. Some studies have also revealed that population belonging to certain ethnic races are more prone to the disease [12].

Sexual History: Women who first become sexually active at an early age (before age 16) are at higher than average risk of developing cervical cancer. In addition, women who have had multiple sexual partners are also at higher risk for cervical cancer. This is because these women are at higher risk of contracting the human papilloma virus (HPV), which cannot be prevented by using condoms or other birth control methods.

$H P V$ : Certain strains of the Human Papilloma Virus (HPV) increase the risk of cervical cancer [2], [19] and [29]. HPV is a common sexually transmitted disease that affects both men and women. There are over 80 different strains of HPV and most do not pose any health risks. However, some strains of HPV (in particular, HPV-16, HPV-18, HPV-31, and HPV-45) can cause cellular changes that may lead to cervical cancer in women. It is estimated that one million new cases of HPV occur each year, and $20 \%$ to $40 \%$ of sexually active women have some form (usually not harmful) of HPV. Women who have abnormal Pap smear results may be specifically tested for HPV.

Smoking: Cigarette smoking may be associated with an increased risk of cervical cancer, as well as other cancers (such as lung) [5]. Physicians have found by-products of tobacco in the cervical mucus of women who smoke and believe these by-products damage the DNA of cervical cells, increasing the risk of cervical cancer. Smokers are twice as likely to develop cervical cancer as non-smokers [1], [7], [8] and [30]. The association between second-hand smoke and cervical intraepithelial neoplasia (CIN) was determined in many studies [4] and [30].

Risk factors associated with breast cancer:

Age and Gender: Besides being female, age is the most important risk factor for breast cancer. Your risk of developing breast cancer increases as you get older. The majority of advanced breast cancer cases are found in women over age 50 . Women are 100 times more likely to get breast cancer than men.

Family History of Breast Cancer: You may also have a higher risk for breast cancer if you have a close relative who has had breast, uterine, ovarian, or colon cancer. About 20 $30 \%$ of women with breast cancer have a family history of the disease [9].

Genes: Some people have genes that make them more prone to developing breast cancer. The most common gene defects are found in the BRCA1 and BRCA2 genes. These genes normally produce proteins that protect you from cancer. But if a parent passes you a defective gene, you have an increased risk for breast cancer. Women with one of these defects have up to an $80 \%$ chance of getting breast cancer sometime during their life [24] and [3].

Menstrual Cycle: Women who get their periods early (before age 12) or went through menopause late (after age 55) have an increased risk for breast cancer [13] and [14].

Other risk factors include:

Alcohol Use: Drinking more than 1 - 2 glasses of alcohol a day may increase your risk for breast cancer [4] and [15].

Childbirth: Women who have never had children or who had them only after age 30 have an increased risk for breast cancer [14]. Being pregnant more than once or becoming 
pregnant at an early age reduces your risk of breast cancer [16].

Living Conditions: Women are at higher risk of breast cancer if they have higher socioeconomic status (SES) or live in higher SES or urban communities [28].

iv. Statistical Analysis: After collecting the data all the data were coded and analyzed by different analytical tools in Statistical Package for Social Sciences (SPSS).

\section{RESULT AND DISCUSSION}

Table 1: gives a summary of the socio-economic status of the patients covered under the study.

Table 1: Socio-Economic Factors of the Patients

\begin{tabular}{|c|c|c|c|c|}
\hline & \multicolumn{2}{|c|}{ Cervix cancer } & \multicolumn{2}{|c|}{ Breast Cancer } \\
\hline & Freq & Percentage & Freq & Percentage \\
\hline \multicolumn{5}{|l|}{ Marital Status } \\
\hline Married & 30 & 100 & 27 & 76.7 \\
\hline Single & 0 & 0 & 3 & 23.3 \\
\hline \multicolumn{5}{|l|}{ Mother tongue } \\
\hline Assamese & 16 & 53.3 & 13 & 43.3 \\
\hline Bengali & 9 & 30.0 & 11 & 36.7 \\
\hline Others & 5 & 16.7 & 6 & 20 \\
\hline \multicolumn{5}{|l|}{ Religion } \\
\hline Hindu & 25 & 83.3 & 22 & 73.3 \\
\hline Muslim & 5 & 16.7 & 8 & 26.7 \\
\hline \multicolumn{5}{|c|}{ Occupation of the guardian } \\
\hline Service holder & 6 & 20.0 & 3 & 10 \\
\hline Business & 7 & 23.3 & 8 & 26.7 \\
\hline Others & 17 & 56.7 & 19 & 63.3 \\
\hline \multicolumn{5}{|l|}{ Family Income } \\
\hline$<5000$ & 16 & 53.3 & 23 & 76.7 \\
\hline$>=5000$ & 14 & 46.7 & 7 & 23.3 \\
\hline \multicolumn{5}{|l|}{ Education } \\
\hline Illiterate & 10 & 33.3 & 9 & 30 \\
\hline Below metric* & 17 & 56.7 & 14 & 46.7 \\
\hline Above metric* & 3 & 10 & 7 & 23.3 \\
\hline \multicolumn{5}{|l|}{ Chewing habit } \\
\hline Betel nut & 11 & 36.7 & 15 & 46.7 \\
\hline $\begin{array}{l}\text { Betel nut and } \\
\text { tobacco }\end{array}$ & 15 & 50 & 6 & 20 \\
\hline $\begin{array}{l}\text { Neither betel } \\
\text { nut nor tobacco }\end{array}$ & 4 & 13.3 & 10 & 33.3 \\
\hline
\end{tabular}

Metric: class 10

The results clearly point out that majority of the respondents in the cervix cancer $(100 \%)$ and breast cancer $(90 \%)$ is married. This gives a suggestion to the fact that post marriage risk factors as well as menopause stage may be associated more with cervix cancer whereas breast cancer develops due to factors arising much before marriage.

Assam has a population of $57.81 \%$ Assamese and $21.67 \%$ Bengalis. It is seen that although higher percentage of respondents belong to Assamese mother tongue (53.3\% and $43.3 \%$ for cervix and breast respectively) there is a relative higher presence of Bengalis $(30 \%$ and $36.7 \%$ for cervix and breast respectively) than the usual population distribution. However religion wise it appears the distribution is maintained somewhat as Assam has $65 \%$ of Hindu population and $31 \%$ Muslims and here it is seen that maximum patient belongs to the Hindu religion $(83.3 \%$ and $73.3 \%$ for cervix and breast respectively).

$56.7 \%$ and $63.3 \%$ of the patients with breast and cervix cancer respectively belong to "other" occupation which includes agri-labours, daily wage earners etc. These are the low-income group occupations and thus may explain the higher presence of patients belonging to this group. This is corroborated in the next category, i.e. family income. The results illustrate that $53.3 \%$ of the respondents from cervical cancer cases has family income less than ₹5000 per month and in the breast cancer cases also majority of the respondent's family (76.7\%) earn less than ₹5000 per month.

Most of the respondents from cervical cancer $(56.7 \%)$ and from breast cancer patients $(46.7 \%)$ belonging to the below metric group.

It is also seen that $50 \%$ of the cervix cancer patients have been using tobacco with betel nut. So this suggests that though not direct smoking, chewing of tobacco may also increase the risk of occurrence of the disease.

Table 2 profiles the different demographical and biological factors which may increase the risk of occurrence of the cervix and breast cancers. The results revealed that most of the cervix cancer patients $(53.3 \%)$ are in the age group greater than 50 . On the other hand in case of breast cancer the opposite picture of it is observed, i.e. $76.7 \%$ of the total breast cancer cases lie in the age group less than 50 . However a previous study made by Bhattacharya et al. [6] revealed that elderly women between 41-50 years of age have significant correlation with the occurrence of cervical cancer.

In this study most of the cervix cancer patients $(56.7 \%)$ diagnosed lies in the greater than 50 years of age group. But in case of breast cancer, $76.7 \%$ of the breast cancer patients are diagnosed in the less than 50 years of age. This is because more breast cancer patients belong to the lower age group than the cervix cancer patients. $73.3 \%$ of the total cervix cancer patient and $43.3 \%$ of the breast cancer patient started their married life before age 20 . While in the cervix cancer group $86.7 \%$ patient have more than 2 children, $46.7 \%$ of the breast cancer group have less than or equal to 2 children. Further in the cervix cancer group, $63.3 \%$ patient got pregnant before age 20 while $63.3 \%$ of the breast cancer patient in the age after 20 . This fact suggests that early marriage and subsequent sexual and reproductive activity has an important part to play in the disease. Likewise a similar picture can be seen in a previous study made by Mhaske, et al [18]. 
Table 2: Demographical and Biological Factors of the Patients

\begin{tabular}{|c|c|c|c|c|}
\hline & \multicolumn{2}{|c|}{ Cervix cancer } & \multicolumn{2}{|c|}{ Breast Cancer } \\
\hline & Frequency & Percentage & Frequency & Percentage \\
\hline \multicolumn{5}{|l|}{ Age } \\
\hline$<=50$ & 14 & 46.7 & & 76.7 \\
\hline$>50$ & 16 & 53.3 & 7 & 23.3 \\
\hline \multicolumn{5}{|c|}{ Age at marriage } \\
\hline$<=20$ & 22 & 73.3 & 13 & 43.3 \\
\hline$>20$ & 8 & 26.7 & 14 & 46.7 \\
\hline Unmarried & - & - & 3 & 10 \\
\hline \multicolumn{5}{|c|}{ No. of Children } \\
\hline$<=2$ & 4 & 13.3 & 14 & 46.7 \\
\hline$>2$ & 26 & 86.7 & 12 & 40 \\
\hline Unmarried & - & - & 4 & 13.3 \\
\hline \multicolumn{5}{|c|}{ Age at first child birth } \\
\hline$<=20$ & 19 & 63.3 & 7 & 23.3 \\
\hline$>20$ & 11 & 36.7 & 19 & 63.3 \\
\hline Unmarried & - & - & 4 & 13.4 \\
\hline \multicolumn{5}{|c|}{ Age at Menarche } \\
\hline$<=12$ & 10 & 33.3 & 15 & 50 \\
\hline$>12$ & 20 & 66.7 & 15 & 50 \\
\hline \multicolumn{5}{|c|}{ Oral contraceptive used } \\
\hline Yes & 14 & 46.7 & 6 & 20 \\
\hline No & 16 & 53.3 & 24 & 80 \\
\hline \multicolumn{5}{|l|}{ Menopause } \\
\hline Yes & 21 & 70 & 11 & 36.7 \\
\hline No & 9 & 30 & 19 & 63.3 \\
\hline \multicolumn{5}{|c|}{ Age at diagnosis } \\
\hline$<=50$ & 13 & 43.3 & 23 & 76.7 \\
\hline$>50$ & 17 & 56.7 & 7 & 23.3 \\
\hline
\end{tabular}

Maximum of the patients (cervix cancer $=53.3 \%$ and breast cancer $=80 \%$ ) does not used oral contraceptive for birth control. However as expected most of the cervix cancer patients $(70 \%)$ have reached menopause.

In Table 3 we give a summary of the associations (chisquares) between the two types of cancers studied and some of the risk factors which have been found to be significantly associated.

The risk factors which have been found to be significant at $5 \%$ level of significance are income of the family of the patients, age of the patient, age at marriage of the patients and oral contraceptive used by the patients. The factors found significant at $1 \%$ level of significance are number of children of the patients and age at first child birth respectively. Many of the previous studies also indicate significant association of these factors with the occurrence of cervical cancer [6] [18] [25] [10].
Table 3: Chi-Square Value and Corresponding p Value Associated with Cancer Type (Ca.Cervix and Ca.Breast) and Different Factors

\begin{tabular}{|l|l|l|}
\hline $\begin{array}{l}\text { Cancer type(Ca.Cervix and Ca.Breast) } \\
* \text { factors }\end{array}$ & $\begin{array}{l}\text { Pearson } \\
\text { Chi- } \\
\text { square } \\
\text { Value }\end{array}$ & -value \\
\hline $\begin{array}{l}\text { Cancer type(Ca.Cervix and Ca.Breast) } \\
\text { *Family income }\end{array}$ & 5.711 & 0.017 \\
\hline $\begin{array}{l}\text { Cancer type(Ca.Cervix and Ca.Breast) } \\
\text { *Age }\end{array}$ & 5.711 & 0.017 \\
\hline $\begin{array}{l}\text { Cancer type(Ca.Cervix and Ca.Breast) } \\
* \text { Age at marriage }\end{array}$ & 6.951 & 0.031 \\
\hline $\begin{array}{l}\text { Cancer type(Ca.Cervix and Ca.Breast) } \\
\text { *No of children }\end{array}$ & 14.713 & 0.001 \\
\hline $\begin{array}{l}\text { Cancer type(Ca.Cervix and Ca.Breast) } \\
\text { *age at } 1 \text { st child birth }\end{array}$ & 11.672 & 0.003 \\
\hline $\begin{array}{l}\text { Cancer type(Ca.Cervix and Ca.Breast) } \\
\text { *oral contraceptives used }\end{array}$ & 4.800 & 0.028 \\
\hline
\end{tabular}

\section{CONCLUSION}

The present study clearly reflects the association between the various risk factors with occurrence of breast and cervix cancers. The factors are: sexual and reproductive factors; socioeconomic factors (income); and other factors such as oral contraceptives. The accumulated evidence suggests that these cancers are preventable and is highly suitable for primary prevention [20]. Raising the age at marriage beyond 18 years, observing small family size, adopting safe sexual practices, attention to personal hygiene of both males and females and use of obstructive methods of contraception could help towards primary prevention of invasive cervical cancer (ICC). In India, due to absence of any organized mass-screening programme, primary prevention measures assume more importance for prevention of uterine cervical cancer [21]. Also improvement in education and socioeconomic status and secondary preventions like screening for uterine cervix and breast cancers can reduce cervical as well as breast cancer morbidity and mortality significantly.

\section{ACKNOWLEDGMENT}

I would like to express my sincere thanks to the Director of Dr. B. Barooah Cancer Research Institute for giving me the permission to collect the data from this institute to continue my research work. And also I am very much grateful to Institute of Advanced Study in Science and Technology for giving me the opportunity to do this study.

\section{REFERENCES}

[1] A. A. I. Alkhair, A. M. Howeida, M. A. I. Ahmed, E. A. Abeer and A. A. Ebtihal, "Impact of tobacco use as a risk factor of cervical cancer among Sudanese women", Sudanese Journal of Public Health, Vol. 3, July 2011.

[2] A. Ferrera, J. P. Velema, M. Figueroa et. al., "Co-factors related to the causal relationship between human papillomavirus and invasive cervical 
cancer in Honduras", International Epidemiological Association 2000. Printed in Great Britain. International Journal of Epidemiology, Vol. 29, Pp. 817-825, 2000.

[3] A. Antoniou, P. D. Pharoah, S. Narod, et al, "Average risks of breast and ovarian cancer associated with BRCA1 or BRCA2 mutations detected in case Series unselected for family history: a combined analysis of 22 studies", American Journal of Human Genetics, Vol. 72, No. 5, Pp. 1117-1130, May 2003

[4] R. Baan, K. Straif, Y. Grosse, et al., "Carcinogenicity of alcoholic beverages", Lancet Oncology. Vol. 8, No. 4, Pp. 292-293, April 2007.

[5] T. M. Becker, C. M. Wheeler, N. S. McGough, C. A. Parmenter, C. A. Stidley, S. F. Jamison, et al. "Cigarette smoking and other risk factors for cervical dysplasia in southwestern Hispanic and Non-Hispanic white women", Cancer Epidemiology, Biomarkers and Prevention, Vol. 3, No. 2, Pp. 113-119, 1994.

[6] S. K. Bhattacharyya, S. Basu, S. Banerjee, A. G. Dastidar, S. R. Bagchi, "An epidemiological survey of carcinoma cervix in north Bengal zone", Journal of Indian Medical Association, Vol. 98, No. 2, Pp. 60-1, 66, February 2000.

[7] P. E. Castle, S. Wacholder, A. T. Lorincz, D. R. Scott, M. E. Sherman, A. G. Glass, et al. "A prospective study of high-grade cervical neoplasia risk among human papillomavirus-infected women". Journal of the National Cancer Institute, Vol. 94, No. 18, Pp. 1406-1414, 2002.

[8] X. Castellsagué, F. X. Bosch, N. Muñoz, "Environmental co-factors in HPV carcinogenesis". Virus Research, Vol. 89, No. 2, Pp. 191-199, 2002.

[9] Collaborative Group on Hormonal Factors in Breast Cancer. "Familial breast cancer: collaborative reanalysis of individual data from 52 epidemiological studies including 58,209 women with breast cancer and 101,986 women without the disease", Lancet, Vol. 358, No. 9291, Pp. 1389-1399, Oct 272001.

[10] J. Cuzick, P. Sasieni and A. Singer, "Risk Factors for Invasive Cervix Cancer in Young Women", European Journal of Cancer, Vol. 32A, No. 5, Pp. 836-841, 1996.

[11] K. A. Dinshaw, D. N. Rao, B. Ganesh, "Tata Memorial Hospital Cancer Registry Annual Report”, Mumbai, India, 1999.

[12] D. O. Edward, S. B. Ross and L. J. Paul. "Cervical cancer mortality in Australia: contrasting risk by Aboriginality, age and rurality", International Epidemiological Association, printed in Great Britain, International Journal of Epidemiology, Vol. 29, Pp. 813-816, 2000.

[13] B. S. Hulka, P. G. Moorman, "Breast cancer: hormones and other risk factors", Maturitas, Vol. 38, No. 1, Pp. 103-113, discussion 113-106, February 282001.

[14] J. L. Kelsey, M. D. Gammon, E. M. John, "Reproductive factors and breast cancer", Epidemiologic Review., Vol. 15, No. 1, Pp. 36-47, 1993.

[15] J. Key, S. Hodgson, R. Z. Omar, et al, "Meta-analysis of studies of alcohol and breast cancer with consideration of the methodological issues", Cancer Causes Control, Vol. 17, No. 6, Pp. 759-770, August 006.

[16] M. Lambe, C. C. Hsieh, H. W. Chan, et al, "Parity, age at first and last birth, and risk of breast cancer: a population-based study in Sweden", Breast Cancer Research and Treatment, Vol. 38, No. 3, Pp. 305-311, 1996.

[17] K. McPherson, C. M. Steel, J. M. Dixon, "ABC of Breast Cancer Epidemiology, Risk Factors, and Genetics", British Medical Journal, Vol. 321, Pp. 624-628, 9 September 2000.

[18] M. Mhaske, S. J. Jawadekar, S. G. Saundale, "Study of Association of some Risk Factors \& Cervical Dysplasia/Cancer Among Rural women", National Journal of Community Medicine, Vol. 2, No. 2, Pp. 209-212, pISSN: 09763325 eISSN: 2229 6816, July-Sept 2011.

[19] N. Muñoz, F. X. Bosch, S. De Sanjosé, R. Herrero, X. Castellsagué, K. V. Shah, P. J. Snijders, C. J. Meijer, "Epidemiologic classification of human papillomavirus types associated with cervical cancer", International Agency for Research on Cancer, Lyons, France. cris@ico.scs.es

[20] N. S. Murthy, A. Mathew, "Cancer epidemiology, prevention and control", Current Science, Vol. 86, No. 4, Pp. 518-524, 2004.

[21] N. S. Murthy and A .Mathew, "Screening for cancer of uterine cervix and approaches adopted in India", Indian Journal of Cancer, Vol. 36, Pp. 154-162, 1999.

[22] A. Nandakumar, National Cancer Registry Program, Indian Council of Medical Research, Consolidated Report of the Population Based Cancer Registries, New Delhi, India: 1990-96.
[23] A. Nandakumar. National Cancer Registry Program, Indian Council of Medical Research, three year report of the Population Based Cancer Registries, New Delhi, India: 2006-08.

[24] G. F. Schwartz, K. S. Hughes, H. T. Lynch, et al. Proceedings of the international consensus conference on breast cancer risk, genetics, \& risk management ,April, 2007, Cancer, Vol. 113, No. 10, Pp. 2627-2637, November 15 2008,

[25] V. Shanta, S. Krishnamurthi , C. K. Gajalakshmi, R. Swaminathan, K. Ravichandran, "Epidemiology of cancer of the cervix: global and national perspective", Jounal of Indian Medical Association, Vol. 98, No. 2, Pp. 49-52, Feb 2000.

[26] A. K. Singh, "Tests. Measurements and Research Methods in Behavioral Science", Published by Bharati Bhavan, Patna, III ${ }^{\text {rd }}$ edition, 1998.

[27] SRS based abridged life tables 1990-94 and 1991-95. SRS Analytical Studies, 1998.

[28] A. R. Stephanie, I. Strombom, A. Trentham-Dietz, J. M. Hampton, J. A. McElroy, P. A. Newcomb, P. L. Remington, "Socio-economic Risk Factors for Breast Cancer: Distinguishing individual and community level Effects", Epidemiology, Vol. 15, No. 4, Pp. 442-450, July 2004. doi: 10.1097/01.ede.0000129512.61698.03

[29] S. Supannee, "The epidemiology of cervical cancer in Khon Kaen, North East Thailand", Academic dissertation, University of Tampere, School of public health, Finland, 2003.

[30] H. T. Tsai, Y. M. Tsai, S. F. Yang, K. Y. Wu, H. Y. Chuang, T. N. Wu, et al. "Lifetime cigarette smoke and second-hand smoke and cervical intraepithelial neoplasm--a community-based case-control study", Gynecologic Oncology, Vol. 105, No. 1, Pp. 181-188, 2007.

[31] WHO, World Health Organisation Annual Report, 1997. 